Revista de

Contabilidade e

Organizações

www.rco.usp.br
DOI: http://dx.doi.org/10.11606/rco.v11i30.134430
Journal of

Accounting and

Organizations

www.rco.usp.br

\title{
Justificativas do turnover de CEOs: Estudo em companhias brasileiras investidas por fundos de pensão
}

CEO' turnover justifications: a study in Brazilian public companies with pension funds as shareholders

Ruben Mendes Matos ${ }^{\mathrm{a}}$; Romualdo Douglas Colauto

${ }^{a}$ Universidade Tuiuti do Paraná

Universidade Federal do Parana

Palavras-chave

CEO.

Turnover.

Justificativas.

Fundos de Pensão.
Keywords

CEO.

Turnover.

Justifications.

Pension Funds.

\section{Informações do Artigo}

Recebido: 13 de julho de 2017

Aceito: 02 de setembro de 2017

\begin{abstract}
Resumo
O estudo identifica as justificativas para o turnover de CEO em companhias de capital aberto no período 2010 a 2014 e mede a intensidade da divulgação dessas justificativas. Para tanto, foi proposto um índice distribuído nas dimensões de divulgação 'forçada e voluntária', a exemplo do estudo de Parrino (1997). A confiabilidade do índice foi medida pelo teste KR-20. A amostra cobriu 65 companhias brasileiras de capital aberto que tinham no mínimo um Fundo de Pensão fechado como acionista. A identificação das justificativas sobre o turnover de CEO foi feita por Análise de Conteúdo. Os resultados para amostra brasileira apontam uma tendência de aumento no turnover quando o desempenho é insatisfatório, corroborando resultados do estudo de Kaplan e Minton (2012). As trocas de CEOs ocorreram predominantemente em companhias com participação societária de fundos de pensão vinculados às empresas estatais. As justificativas de 'desempenho insatisfatório' e 'atuação exclusiva no conselho' (não acumulo de cargos executivos) foram as mais divulgadas na mídia especializada.
\end{abstract}

\begin{abstract}
The article provides the justifications for CEO's turnover in Brazilian public (listed) companies from 2010 to 2014, and it measures the disclosure intensity of these justifications. An index in two dimensions for justification 'voluntary and forced' was proposed according to Parrino (1997). The index reliability was measured by KR-20 test. The sample covered 65 Brazilian public companies which have at least one pension fund as shareholder. Content analysis was applied to identify the CEO's turnover justifications. Corroborating Kaplan and Minton (2012), the results for Brazilian companies presented a growing trend towards turnover for cases of unsatisfactory performance. The CEOs' turnover occurred predominantly in companies in which the shareholder was a pension funds from State-owned companies. The main justifications disclosed by specialized press were 'Unsatisfactory Performance' and 'act exclusively as board member' (do not accumulate executive positions).
\end{abstract}

Copyright $(2017$ FEA-RP/USP. Todos os direitos reservados

\section{INTRODUÇÃO}

No ambiente sensível das Bolsas de Valores os eventos relevantes impactam nas decisões dos investidores sobre comprar, vender ou manter as suas posições, influenciados por fatores exógenos que contribuem substancialmente para a determinação do valor das ações. Um dos eventos que tem potencial para influenciar as decisões dos investidores é a mudança de $C E O$, pois este atua no sentido de concretizar os objetivos e metas traçadas pelo Conselho de Administração.

A Lei 6.404/76 estabelece que os administradores das companhias abertas são obrigados a comunicar imediatamente à bolsa de valores e a divulgar pela imprensa qualquer fato relevante ocorrido nos seus negócios, que possa influir, de modo ponderável, na decisão dos investidores do mercado de vender ou comprar valores mobiliários emitidos pela companhia. A mudança de $C E O$ em uma companhia tende a impactar na gestão da empresa e consequentemente na precificação dos seus títulos no mercado, positiva ou negativamente, dependendo, entre outros fatores da justificativa da troca de comando. Em decorrência disto, os investidores revisam suas expectativas sobre o valor da empresa em razão da relevância do papel do $C E O$ (Cheung \& Jackson, 2012). 
Um grupo relevante destes investidores são os Fundos de Pensão Fechados. Estes players são investidores institucionais, regulados e sofisticados e detinham no primeiro quadrimestre de 2017 aproximadamente R\$ 812 bilhões em ativos, o equivalente a 12,8\% do Produto Interno Bruto (ABRAPP, 2017).

Determinadas notícias divulgadas pelas mídias ao mercado sobre as justificativas que levaram a troca do $C E O$ podem ser mais intensamente divulgadas do que outras e a maior ou menor intensidade de divulgação influencia as decisões dos investidores. As trocas de CEOs apresentam justificativas relacionadas ao ambiente econômico, social ou político e estas tendem a interferir na avaliação e percepção do investidor. Nesse sentido, o objetivo da pesquisa consiste em identificar as justificativas do turnover do CEO e elaborar uma métrica para medir a intensidade da divulgação destas justificativas no mercado brasileiro no período 2010-2014.

Murphy e Zabonjik (2007) relataram que o turnover de CEOs aumentou nos Estados Unidos na década de 1990 em relação aos anos 1970 e 1980. Afirmaram que o turnover foi em média de 10\% ao ano nas décadas de 1970 e de 1980 e de $11 \%$ na década de 1990. Kaplan e Minton (2012) constataram que aproximadamente 64\% dos Presidentes das companhias que estavam no cargo em 1992 não permaneceram em 1997, e somente $25 \%$ daqueles que estavam no cargo em 1998 permaneceram em 2003. No Brasil, os estudos sobre o reflexo da mudança de comando ainda são incipientes.

Parrino (1997) foi precursora em estabelecer classificações para a troca de $C E O$. A pesquisadora dividiu os eventos explicativos em duas dimensões: Forçada e Voluntária. A divisão é arbitrária e não consensual entre os pesquisadores. Alguns estudos tentaram mitigar a arbitrariedade inserindo elementos de objetividade, para tanto, adotam as informações publicadas em mídia especializada para se aproximar da efetiva razão da troca do CEO. Dissanaike e Papazian (2004) reconheceram em suas pesquisas as dificuldades de classificar de forma objetiva e precisa as saídas do $C E O$ entre forçadas e voluntárias. Isto ocorre porque as empresas tendem a ocultar os verdadeiros motivos da troca, utilizando expressões evasivas ou vagas, não fornecendo nenhuma razão para a troca ou ainda declarando outras justificativas diferentes das verdadeiras.

Worrell, Davidson e Glascock (1993) Engel, Hayes e Wang (2003) classificaram as notícias sobre turnover de $C E O$ em forçada para os casos em que houve declaração explícita para demissão, conflito ou em que o gestor foi convidado a se demitir e as demais justificativas como voluntárias. Cheung e Jackson (2012) criticaram esse método de classificação porque este dependente de detalhes fornecidos pela empresa no anúncio, falhando para capturar casos em que as empresas evitam deliberadamente explicitar a natureza da saída. Uma alternativa encontrada foi buscar nas mídias especializadas as razões para a mudança, a exemplo dos estudos de Bushman, Dai e Wang (2010) ao buscaram as notícias no Factiva news database e Parrino (1997), que buscou as notícias sobre as mudanças do CEO no Wall Street Journal.

Embora as pesquisas tenham classificado as justificativas entre forçadas e voluntárias, essas não têm avaliado a intensidade da divulgação da justificativa do turnover. É este espaço que a pesquisa pretende preencher. Neste sentido o estudo apresenta três contribuições importantes para os estudos no cenário nacional: identifica as justificativas para a troca no comando nas companhias brasileiras; propõe uma métrica para medir a intensidade da divulgação destas justificativas; e oportuniza que outros pesquisadores venham a utilizar esta métrica para verificar as correlações entre a intensidade da divulgação e os retornos anormais observados no mercado de capitais.

\section{REFERENCIAL TEÓRICO}

O mercado de capitais classifica os investidores em dois grandes grupos: os investidores sofisticados e os investidores ingênuos. Os investidores ingênuos tendem a atribuir maior importância ao desempenho histórico das empresas como critério de decisão de investimento (James \& Karceski, 2002; Del Guercio \& Tkac, 2002; Gomes, 2014). Por outro lado, os grandes investidores institucionais são considerados bem informados, obtendo economias de escala na produção de informação e participação ativa no mercado. Menores custos de pesquisas para esses grandes investidores institucionais permitem a utilização de instrumentos de avaliação e de precificação mais sofisticados (James \& Karceski, 2002).

Fletcher (1988) explica que o investidor sofisticado evita erros comuns dos pequenos investidores ao afirmar que eles detêm vastos recursos e possuem profissionais formados nas melhores escolas de negócios do mundo, além de substancial experiência no mercado de capitais. Para Hand (1990), os investidores institucionais avaliam melhor os lucros divulgados, além de serem mais capacitados para identificar desvios sistemáticos nos lucros. 
Boehmer e Kelley (2009) destacam que as ações com maior propriedade institucional apresentam preços mais consistentes em função de que os investidores institucionais são mais eficientes no processamento das informações. Os Fundos de Pensão integram o grupo de investidores sofisticados em face do volume de recursos que administram.

Os maiores Fundos de Pensão do país têm vínculos com sociedades de economia mista ou empresas públicas. O PREVI, o maior Fundo de Pensão fechado do país, é patrocinado pelo Banco do Brasil, uma sociedade de economia mista. O segundo maior, a PETROS, pela Petrobras, outra sociedade de economia mista e o terceiro, o FUNCEF, pela Caixa Econômica Federal, uma empresa pública federal. Entre os 20 maiores Fundos de Pensão fechados do país, 8 eram patrocinados por entidades controladas pela administração pública, o que representava aproximadamente 42,0\% dos ativos totais dos Fundos de Pensão em abril de 2017. De Dreu e Bikker (2012) constataram que na Holanda o total dos ativos dos Fundos de Pensão em 2010 representava 132\% do PIB daquele país, o maior do mundo em termos proporcionais.

Em razão do marco regulatório a que os Fundos de Pensão estão submetidos, o Conselho Monetário

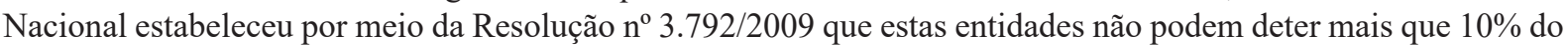
capital de uma companhia aberta. No entanto, isto não impede que os Fundos possam compor o bloco de controle por meio de acordo de acionistas, mas este aspecto não compõe o objeto do presente estudo. O principal executivo de uma companhia tende a permanecer no cargo por determinado período de tempo, mais ou menos longo a depender de alguns fatores. Cheung e Jackson (2012) afirmam que a maioria deles são considerados uma face pública da empresa e a troca do $C E O$ pode representar uma mudança nesta face e ser vista como uma ruptura que tende a gerar inquietações e instabilidades no mercado.

Nas últimas décadas foram efetuadas pesquisas sobre a relação entre o turnover de $C E O$ e o desempenho da empresa. Esta relação implica em reconhecer que existe um mecanismo de incentivo para que os CEOs alinhem seus interesses com os dos acionistas, e esta relação é geralmente considerada negativa (Murphy \& Zimmerman, 1993; Kang \& Shivdasani, 1995; Denis, Denis \& Sarin, 1997; Defond \& Park, 1999; Lausten, 2002; Brunello, Graziano \& Parigi, 2003; Huson, Malatesta \& Parrino, 2004). A morte de um CEO ou seu afastamento por doença, geralmente é um evento surpreendente. Johnson, Magee, Nagarajan e Newman (1985) analisaram 53 eventos de morte súbita de $C E O$ no período de 1971 a 1982. O resultado mostrou que súbitas mortes de CEOs têm pouco impacto sobre o retorno de ações ordinárias, mas retornos excedentes foram caracterizados, sugerindo que ocorram ajustes de preços positivos e negativos para as mortes dos CEOs.

As pesquisas de Agrawal, Jaffe e Karpoff (1999) encontraram evidências fracas de turnover de CEOs nas circunstâncias de ocorrências de fraudes contábeis e corrupção corporativa. As justificativas determinantes para a troca do Diretor Presidente são variáveis no tempo. A Regulação é uma justificativa que pode acarretar a saída do $C E O$. Por exemplo, BMF\&Bovespa determinou para os níveis de governança corporativa diferenciados que as mesmas pessoas não poderiam exercer simultaneamente a função de $C E O$ e de Presidente do Conselho de Administração. Em função disto, muitos $C E O s$ que acumulavam as funções foram afastados de uma delas e, em muitos casos, para permanecer somente na Presidência do Conselho. As mudanças políticas que ocorrem no Poder Executivo podem impactar na gestão das companhias em que a Administração Pública detenha participação significativa no capital. A maioria das mudanças tem origem em arranjos políticos e acarretam a troca do principal executivo.

Os participantes do mercado passaram a ter acesso a informações dos relatórios dos analistas financeiros, anúncios anteriores e comentários da mídia especializada, diminuindo a dependência da informação fornecida pelas empresas e assim viabilizando outras fontes para a formação de opiniões sobre a efetiva razão para a saída do $C E O$. Cheung e Jackson (2012) examinaram se os efeitos da volatilidade dos retornos resultantes da saída do CEO diferem entre saídas voluntárias e forçadas no contexto australiano. Os autores criticaram os estudos anteriores porque teriam como base somente o anúncio oficial emitido pela empresa e que talvez ocultasse os verdadeiros motivos da saída. Assim, afirmam que a metodologia empregada por eles apresenta melhor consistência estatística em relação as pesquisas anteriores.

A composição das justificativas do turnover está dividida em (1) forçada e (2) voluntária. Esta divisão está alinhada aos procedimentos adotados por Parrino (1997), Bushman et al. (2010) e Cheung e Jackson (2012). As justificativas de natureza voluntária tendem a ter baixa ocorrência em razão da tendência natural do $C E O$ se proteger no Conselho das companhias. Parte dos motivos da proteção pode ser explicada pelo fato de que há empresas ao redor do mundo controladas por famílias, sendo natural que o CEO seja de origem da família controladora, o que explicaria certo continuísmo, mesmo diante de um mau desempenho (Faccio \& Lang, 2002; Rachpradit, Tang \& Ba Khang, 2012). 


\section{PROCEDIMENTOS METODOLÓGICOS}

Os dados da população das companhias foram coletados de duas formas distintas. Primeiramente foram identificadas, por meio da análise dos relatórios de referência, quais companhias brasileiras de capital aberto pertencentes ao IBOVESPA que tiveram turnover de CEOs no período 2010-2014 e as respectivas datas. Depois foram identificadas quais dessas empresas possuíam entre seus acionistas um Fundo de Pensão Fechado.

Neste estudo foram pesquisadas as notícias disponíveis na plataforma do Bloomberg ${ }^{\circledR}$ e complementadas nas mídias Exame, ComDinheiro e Valor Econômico, as quais foram analisadas por meio da técnica de Análise de Conteúdo. O objetivo foi verificar a ocorrência de termos selecionados dentro de um texto ou textos, sendo estes implícitos ou explícitos.

Para identificar as justificativas do turnover de $C E O$ foi adotado o protocolo de Bardin (2010), seguindo os seguintes procedimentos: 1) identificação preliminar das datas em ocorreram o turnover por meio da análise dos comunicados que as companhias enviaram para a BMF\&Bovespa e Comissão de Valores Mobiliários - CVM; 2) separação e organização das notícias para serem submetidas ao ATLAS.ti ${ }^{\circledR}$ para mitigar a subjetividade. As expressões e sinônimos utilizados na pesquisa estão sintetizadas no Quadro 1.

\begin{tabular}{|c|c|}
\hline DIMENSÕES/JUSTIFICATIVAS & EXPRESSÕES E SINÔNIMOS \\
\hline \multicolumn{2}{|c|}{ TURNOVER FORÇADO } \\
\hline $\begin{array}{c}\text { Desempenho Econômico, Financeiro ou Estratégico } \\
\text { Insatisfatório }\end{array}$ & Desempenho, performance, desafios, resultados. \\
\hline Decorrente de Doença & Doença, ataque, adoecimento, enfermidade, moléstia. \\
\hline Decorrente de Morte & Morte, desaparecimento, óbito, passamento, falecimento. \\
\hline $\begin{array}{l}\text { Deixar o cargo para permanecer apenas no Conselho de } \\
\text { Administração }\end{array}$ & $\begin{array}{l}\text { Novo Mercado, Nível 1, Nível 2, Marco Regulatório, } \\
\text { Regulação, permanência no Conselho. }\end{array}$ \\
\hline Decorrente de Fraude Contábil ou Corrupção Corporativa & $\begin{array}{l}\text { Fraude, golpe, falcatrua, tramoia, farsa, embuste, burla, } \\
\text { corrupção, adulteração, deturpação. }\end{array}$ \\
\hline Decorrente de novas regulações do Sistema Financeiro & Regulação, Banco Central, regulagem. \\
\hline Provocado por Mudanças Políticas de Governo & $\begin{array}{c}\text { Mudança, troca, alteração, alternância, mandatário, } \\
\text { Presidente. }\end{array}$ \\
\hline Decorrente de Reestruturação Organizacional & Reorganização, reestruturação, reforma, renovação. \\
\hline
\end{tabular}

\section{TURNOVER VOLUNTÁRIO}

\begin{tabular}{cc}
\hline Decorrente de Aposentadoria & Aposentadoria, retirada, afastamento, inatividade. \\
Motivado por Causas Pessoais & Convite para outra companhia, problemas na família. \\
\hline
\end{tabular}

Quadro 1 - Expressões e Sinônimos empregados na Anállise de Conteúdo

Fonte: Elaborado pelos autores com base em Parrino (1997)

Para a construção do índice de intensidade de divulgação das justificativas do turnover do CEO foram elaboradas 11 proposições. A ideia foi prover um índice que capturasse a amplitude da divulgação das notícias sobre a troca de $C E O$. O pressuposto é de que quanto mais ampla for a divulgação sobre as justificativas da troca de $C E O$ mais importante seria o evento para os investidores institucionais. As proxies utilizadas para quantificar a intensidade da divulgação estão apresentadas no Quadro 2. 
P01: A notícia tem manchete sobre turnover de CEO

P02: A mídia é exclusiva da área econômica

P03: A notícia é de dia diferente à reunião do Conselho sobre turnover do $C E O$

P04: Mais de uma notícia divulgada

P05: Há mais de uma notícia no mesmo dia

P06: A notícia sobre turnover do $C E O$ é exclusiva

P07: A notícia está publicada na Bloomberg

P08: A notícia está divulgada na Bloomberg e em outros meios

P09: A mesma notícia está repetida na Bloomberg em mais de um dia

P10: A mesma notícia está replicada em outros meios, além da Bloomberg, na mesma data

P11: Há notícias na Bloomberg em mais de um dia e em outros meios

Quadro 2 - Proxies para quantificar a intensidade da divulgação das justificativas do tunorver do CEO

Fonte: Elaborado pelos autores

As notícias sobre o turnover do $C E O$ foram agrupadas em função das justificativas de turnover. Quando a resposta confirmou a proposição foi atribuída 1 (um) ponto e 0 (zero) quando negativa. Desta forma, quanto maior a pontuação da notícia maior foi a amplitude de sua divulgação. O índice para cada proposição foi apurado pela divisão da pontuação absoluta pela pontuação máxima possível (11).

Posteriormente foi apurada a média aritmética de cada proposição para cada justificativa. Para testar a confiabilidade do índice foi utilizado o Kuder-Richardson-20 (KR-20), coeficiente utilizado em instrumentos de pesquisa para formatos com respostas dicotômicas. Quanto mais próximo de um (1) maior é a confiabilidade do instrumento. $\mathrm{O}$ resultado do teste indicou que o KR-20 foi de 0,638. Este resultado indica consistência interna do instrumento, considerando que ser aceitável o KR-20 superior a 0,6 (Maroco \& Garcia-Marques, 2006).

\section{APRESENTAÇÃO E DISCUSSÃO DOS RESULTADOS}

A pesquisa localizou 65 eventos de turnover de $C E O$ no período pesquisado. Constatou-se que as mídias não reportaram notícias sobre a justificativa da troca em aproximadamente $50 \%$ dos eventos. Este achado denota baixo nível de divulgação dessas informações aos stakeholders em relação a um conjunto de empresas. Em relação as 33 companhias que divulgaram, 30 ocorreram naquelas em que havia participação de fundos de pensão vinculados as companhias estatais. A participação maciça dos fundos estatais nas trocas dos $C E O s$ é uma consequência da relevante participação destes fundos no mercado de capitais. Na Tabela 1 apresentam-se as justificativas e a quantidade de turnover no período: 
Tabela 1. Justificativas e Turnover

\begin{tabular}{|c|c|c|c|}
\hline \multirow{2}{*}{ Justificativas } & \multirow{2}{*}{ Total } & \multicolumn{2}{|c|}{$\begin{array}{l}\text { Participação de fundos de pensão } \\
\text { fechados }\end{array}$} \\
\hline & & estatais & não estatais \\
\hline Total de eventos de turnover observados & 65 & 61 & 4 \\
\hline Total das Justificativas divulgadas & 33 & 31 & 2 \\
\hline \multicolumn{4}{|l|}{ Dimensão forçada } \\
\hline Desempenho Insatisfatório & 12 & 11 & 1 \\
\hline Decorrente de Doença & 0 & 0 & 0 \\
\hline Decorrente de Morte & 0 & 0 & 0 \\
\hline Permanência apenas no Conselho de Administração & 13 & 12 & 1 \\
\hline Decorrente de Fraude Contábil ou Corrupção Corporativa & 0 & 0 & 0 \\
\hline Mudanças Políticas de Governo & 5 & 5 & 0 \\
\hline Reestruturação do Board & 1 & 1 & 0 \\
\hline Regulação do Sistema Financeiro & 1 & 1 & 0 \\
\hline \multicolumn{4}{|l|}{ Dimensão voluntária } \\
\hline Aposentadoria & 1 & 1 & 0 \\
\hline Motivado por Causas Pessoais & 0 & 0 & 0 \\
\hline Total de justificativas não divulgadas & 32 & 30 & 2 \\
\hline
\end{tabular}

Fonte: Elaborada pelos autores

Os administradores de companhias abertas estão obrigados a comunicar imediatamente à bolsa de valores e a divulgar pela imprensa qualquer deliberação da assembleia-geral ou dos órgãos de administração da companhia, ou fato relevante ocorrido nos seus negócios, que possa influir, de modo ponderável, na decisão dos investidores do mercado de vender ou comprar valores mobiliários emitidos pela companhia ( $\S 4^{\circ}$ Art. 157, Lei 6.404/76). No entanto, aproximadamente $50 \%$ das companhias pesquisadas não demonstram interesse em divulgar efetiva e tempestivamente as justificativas para a troca do $C E O$, sejam estas forçadas ou voluntárias. Uma possível explicação seria em razão de que 36\% das justificativas refiram-se a "Desempenho Insatisfatório" e isto poderia caracterizar uma má notícia (bad news) para o mercado.

A justificativa "Permanência apenas no Conselho de Administração" de caráter eminentemente normativo, decorrentes de mudanças no marco regulatório da bolsa de valores, e de conhecimento dos investidores institucionais, portanto, com menor poder de interferir em decisões de investimentos, representou aproximadamente $39 \%$ das trocas no período.

Observa-se que as justificativas para troca de CEOs estavam concentradas em três categorias: (i) Desempenho Insatisfatório; (ii) Permanência do $C E O$ apenas no Conselho de Administração e (iii) Mudanças Políticas de Governo. Estas justificativas representaram aproximadamente 80,0\% do total identificado como explicações para a troca dos executivos. Não foram localizadas turnover decorrentes de morte, doença, corrupção, fraude ou justificativas de natureza pessoal.

A justificativa "Desempenho Insatisfatório" representou aproximadamente 36\% das trocas, mas, quando desconsiderada a justificativa "Permanecer apenas no Conselho de Administração", em razão do seu caráter transitório, representaria aproximadamente $63 \%$ do turnover do período. Esta constatação de que a justificativa "Desempenho" é a causa para a maioria das trocas de CEOs está alinhada com os resultados das pesquisas de Bushman et al. (2010) e Jenter e Lewellen (2014). Jenter e Kanaan (2015) confirmaram que os CEOs são mais propensos a serem demitidos em razão do mau desempenho.

Na Tabela 2 apresentam-se os quantitativos das notícias e turnover distribuídos ao longo do tempo. 
Tabela 2. Quantidade de Notícias e Turnover

\begin{tabular}{|c|c|c|c|c|c|}
\hline \multirow[b]{2}{*}{ Ano } & \multirow[b]{2}{*}{ Total de Turnover } & \multicolumn{2}{|c|}{$\begin{array}{l}\text { Participação de fundos de } \\
\text { companhias estatais }\end{array}$} & \multicolumn{2}{|c|}{ Participação de outros fundos } \\
\hline & & Turnover & Notícias & Turnover & Notícias \\
\hline 2010 & 2 & 2 & 3 & 0 & 0 \\
\hline 2011 & 6 & 6 & 9 & 0 & 0 \\
\hline 2012 & 5 & 5 & 13 & 0 & 0 \\
\hline 2013 & 11 & 11 & 25 & 0 & 0 \\
\hline 2014 & 9 & 7 & 14 & 2 & 2 \\
\hline Total & 33 & 31 & 64 & 2 & 2 \\
\hline
\end{tabular}

Fonte: Elaborada pelos autores

Os Fundos de Pensão integram o seleto grupo de investidores sofisticados em face do volume de recursos que administram. Entre os Fundos de Pensão fechados do país em abril de 2017, os 3 maiores fundos (PREVI, PETROS, FUNCEF) vinculados à administração pública federal, representavam aproximadamente 37,0\% do total dos ativos destes investidores institucionais. Além disso, os 20 maiores fundos, de um total de 261, somavam em abril de 2017, um montante de aproximadamente 65\% dos ativos totais dos Fundos de Pensão fechados no Brasil. A participação significativa destes fundos no mercado de capitais pode explicar o fato de que a maioria das justificativas para o turnover (94\%) ocorreram em companhias em há a participação de fundos estatais.

A Regulação é uma justificativa que acarretou a maior parte da troca de CEOs nas empresas analisadas e fez muitos CEOs permanecerem apenas no Conselho de Administração. A BMF\&Bovespa determinou para os níveis de governança corporativa diferenciados que as mesmas pessoas não poderiam exercer simultaneamente a função de $C E O$ e de Presidente do Conselho de Administração. Esta justificativa é de caráter temporário e pontual, cuja normatização independe da participação dos fundos nas companhias, pois trata-se de uma regulação geral aplicável a todas as companhias brasileiras de capital aberto. Neste aspecto prevalece as especificidades da regulação brasileira, que diverge de estudos internacionais precedentes neste ponto, inviabilizando a comparação com achados anteriores. Em 2013 foi registrado que 46\% das mudanças de todas as trocas de comando ocorreram em função desta justificativa. Esta concentração foi decorrente da decisão de muitas companhias realizarem a mudança no último ano do prazo estabelecido. Observou-se ainda predomínio do turnover em companhias em que havia participação dos fundos de pensão estatais em razão da expressiva participação destes fundos no mercado de capitais. Desta forma, esta justificativa não está relacionada diretamente com a participação dos fundos, pois a regulação foi dirigida para todas as companhias, independentemente das características dos seus acionistas serem fundos estatais ou não estatais.

Em relação ao turnover dos CEOs decorrente de desempenho insatisfatório, estes resultados podem ser comparados com os estudos anteriores que remetem sua justificativa para diversos pontos: cultura de concorrência (Fiordelisi \& Ricci, 2014); desempenho do mercado também ser ruim (Jenter \& Kanaan, 2015); fraco desempenho nos primeiros anos de mandato (Jenter \& Lewellen, 2014); baixo ou alto otimismo dos CEOs serem mais propensos ao turnover forçado (Campbell, Gallmeyer, Johnson, Rutherford \& Stanley, 2011).

Outro ponto que merece destaque é que no Brasil não há uma cultura explicitada de ativismo dos acionistas institucionais. No mercado americano este ativismo é reconhecido como forte e explicita a influência dos Fundos de Pensão na condução das grandes empresas em que investem (Kaplan \& Minton, 2012). No entanto, de acordo com Punsuvo, Kayo e Barros (2007), mesmo quando os fundos de pensão não agem publicamente, os gestores contratados para administrar seus recursos aparentemente conseguem influenciar sobre a saída de alguns dirigentes em função do desempenho corporativo. A maior participação de Fundos Estatais (31 x 2) mostrados na Tabela 1, em detrimento de fundos não estatais, pode sinalizar a existência de um ativismo efetivo, mas não explicito dos Fundos de Pensão estatais, que podem pressionar pela troca do $C E O$ quando os resultados não forem julgados satisfatórios.

Os casos de mudança de $C E O$ em decorrência de "mudanças políticas de Governo", ocorreram em Companhias em que havia predomínio de participação de fundos estatais, além da participação direta do Tesouro, tais como Eletrobras e Petrobras. A imprensa divulgou que estas mudanças decorreram de indicações partidárias ou pessoais da Presidência. Não se pode afirmar ou negar que os Fundos tenham exercido seu poder de influência ou ativismo nestas mudanças. 
Tabela 3. Índice da Intensidade da Divulgação das Notícias sobre as Justificativas do Turnover de $C E O$

\begin{tabular}{|c|c|c|c|c|c|c|c|c|c|c|c|c|c|}
\hline $\begin{array}{l}\text { PROPOSIÇÕES/ } \\
\text { JUSTIFICATIVAS }\end{array}$ & 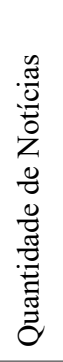 & 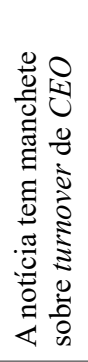 & 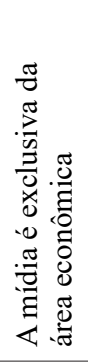 & 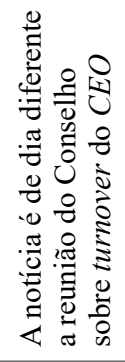 & 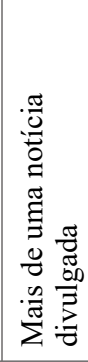 & 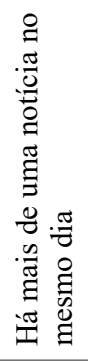 & 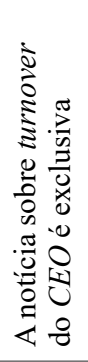 & 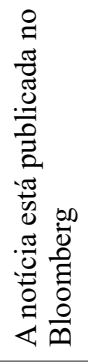 & 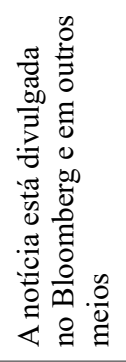 & 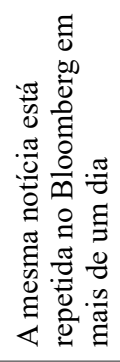 & 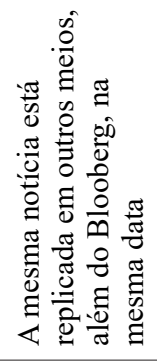 & 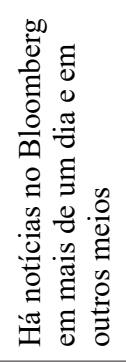 & 点 \\
\hline \multicolumn{14}{|l|}{ DIMENSÃO FORÇADA } \\
\hline $\begin{array}{r}\text { Desempenho Econômico, } \\
\text { Financeiro ou Estratégico } \\
\text { Insatisfatório }\end{array}$ & 32 & 1 & 0,94 & 1 & 0,88 & 0,59 & 0,94 & 0,34 & 0,19 & 0,16 & 0,47 & 0 & 0,59 \\
\hline $\begin{array}{r}\text { Deixar o cargo para permanecer } \\
\text { apenas no Conselho de } \\
\text { Administração }\end{array}$ & 20 & 0,95 & 0,95 & 1 & 0,60 & 0,25 & 0,90 & 0,20 & 0,05 & 0 & 0,15 & 0,05 & 0,46 \\
\hline $\begin{array}{r}\text { Provocado por Mudanças } \\
\text { Políticas de Governo }\end{array}$ & 8 & 0,75 & 0,75 & 1 & 0,63 & 0,25 & 0,88 & 0,63 & 0,13 & 0,25 & 0,25 & 0 & 0,50 \\
\hline $\begin{array}{r}\text { Decorrente de novas Regulações } \\
\text { no Sistema Financeiro }\end{array}$ & 2 & 1 & 1 & 1 & 1 & 0 & 1 & 0 & 0 & 0 & 0 & 0 & 0,45 \\
\hline $\begin{array}{r}\text { Decorrente de Reestruturação do } \\
\text { Board }\end{array}$ & 3 & 1 & 1 & 1 & 1 & 1 & 1 & 0,33 & 0,33 & 0 & 1 & 0 & 0,70 \\
\hline MÉDIA & & 0,94 & 0,93 & 1 & 0,82 & 0,42 & 0,94 & 0,30 & 0,14 & 0,08 & 0,37 & 0,01 & \\
\hline \multicolumn{14}{|l|}{ DIMENSÃO VOLUNTÁRIA } \\
\hline Decorrente de aposentadoria & 1 & 0 & 0 & 0 & 0 & 0 & 0 & 0 & 0 & 0 & 1 & 0 & 0,09 \\
\hline$M E ́ D I A$ & & 0 & 1 & 0 & 0 & 0 & 0 & 0 & 0 & 0 & 1 & 0 & \\
\hline
\end{tabular}

Fonte: Elaborado pelos autores 
Para elucidar o turnorver de CEO's apresentam-se três casos icônicos cujos reflexos permanecem ainda em 2017. A empresa OI S.A., que atua na área de telecomunicações, trocou seu $C E O$ em 2014 em razão do desempenho. Mas esta troca não foi suficiente para melhorar os resultados da Companhia porque em 2016 foi solicitada ao Poder Judiciário a sua Recuperação Judicial, cujos desdobramentos ainda são imprevisíveis. Em 2012, uma das maiores companhias brasileiras, a Petrobras, teve como CEO pela primeira vez uma mulher. A troca do $C E O$ pela Graça Foster teve como fundamento uma decisão de caráter eminentemente político da então Presidente da República. Quando assumiu o cargo ela tornou-se integrante de um seleto grupo de mulheres no comando de grandes empresas do mundo. A lista das 500 maiores empresas do mundo em valor de mercado, divulgada pela revista Fortune, indicava que somente 12 destas Companhias eram chefiadas por mulheres e ela era a única no setor petrolífero.

Esta mudança não foi suficiente para deter um dos maiores escândalos de corrupção do mundo. A operação do Poder Judiciário "Lava Jato" perdura até o momento com a apuração de crimes de corrupção ativa e passiva, resultando em prisões e condenações de empresários e políticos de vários escalões da República. Outra troca de $C E O$ icônica foi na Companhia Estácio Participações, que atua na área de educação, que trocou em 2012 seu $C E O$ por força da regulação do mercado de capitais. O CEO que acumulava este cargo com o de Presidente do Conselho de Administração permaneceu somente na Presidência do Conselho. Em 2017 o projeto de fusão da Companhia com a Kroton, outra gigante do setor, que resultaria na maior Companhia de educação privada do país, não foi autorizado pelo Conselho Administrativo de Defesa Econômica - CADE, em razão da concentração que haveria no setor de educação privada.

Para medir a intensidade da divulgação das justificativas do turnover dos CEOs foram utilizadas as proxies demonstradas no Quadro 2. As proposições que obtiverem maior número de respostas "Não" corresponderam a um índice mais próximo de 0 (zero), enquanto as proposições com maior número de respostas "Sim" corresponderam a um índice próximo de 1 (um). Para melhor análise dos dados e compreensão dos resultados estes foram dispostos em função do agrupamento das justificativas. Na Tabela 3 apresentam-se a composição do índice de cada item analisado.

A Análise de Conteúdo das notícias sobre o turnover indicou que as justificativas mais frequentes encontradas na pesquisa decorreram do mau desempenho e da saída do $C E O$ por força da regulação do mercado de capitais. Dos eventos veiculados na mídia, 31 referem-se a troca de $C E O$ s de companhias com participação de fundos de pensão fechados estatais e apenas 2 não estatais. Esta concentração de turnover tendo como justificativa o "desempenho" pode estar associada ao ativismo não explícito dos Fundos de Pensão estatais.

Em relação à veiculação das 66 notícias, observou-se o comportamento da intensidade da divulgação dos eventos referente as motivações da dimensão forçada: a) todas as notícias divulgadas ocorreram em dias diferentes da data de reunião do conselho de administração, resultando em um índice de intensidade de divulgação igual a 1 ; b) para as proposições a "notícia teve manchete sobre turnover de CEO" e "a notícias sobre o turnover do CEO foi exclusiva", a média de intensidade da divulgação foi de 0,94 , denotando a importância do evento para as mídias especializadas; c) para a proposição "a mídia é exclusiva da área econômica", a média de intensidade de divulgação foi de 0,93 , significando maior interesse de veículos de divulgação específicos da área do mercado financeiro; d) em relação em haver mais de uma notícia divulgada, a intensidade média foi de 0,82 , o que mostra uma preocupação das mídias pesquisadas em veicular notícias sobre a troca de CEOs.

No entanto, estas notícias se dispersam na veiculação ao longo da janela de eventos, considerando que a sua média de intensidade de divulgação é reduzida a 0,42 ; e) as proposições "a notícia está publicada na base Bloomberg $®$ e em outros meios" e "a mesma notícia esta replicada em outros meios, além da base Bloomberg ${ }^{\circledR}$ na mesma data" tiveram intensidade de divulgação média de 0,30 e 0,37 respectivamente, denotando tempestividade da base Bloomberg® em noticiar eventos com potencial de interferir nas decisões dos investidores institucionais.

Todavia, outros mídias não atribuíram a mesma importância às notícias de turnover, uma vez que o índice médio de intensidade de divulgação foi de apenas 0,14 ; f) quanto à intensidade de permanência das veiculações das notícias ao longo da janela temporal estudada, notou-se índice médio de 0,08 para proposição "a mesma notícia está repetida no Bloomberg ${ }^{\circledR}$ em mais de um dia" e índice médio de 0,01 para a proposição "haver notícia no Bloomberg ${ }^{\circledR}$ em mais de um dia e em outros meios", ficando novamente clara a efemeridade das notícias sobre a troca de CEOs em companhias que possuem Fundos de Pensão em seu quadro de investidores institucionais.

As justificativas das trocas na Dimensão Forçada que tiveram menor índice de divulgação foram "Deixar o Cargo para Permanecer apenas no Conselho de Administração" e "Decorrente de novas Regulações no Sistema Financeiro". É natural que ocorra uma propagação em outras mídias das notícias consideradas mais importantes. É nesse sentido que a proposição que avalia se há mais de uma notícia no mesmo dia foi inserida. 
O resultado mostrou que as notícias sobre as justificativas da troca em decorrência da "Reestruturação do Board" e do "Desempenho" tiveram mais divulgação em função de terem mais de uma notícia sobre o mesmo assunto no mesmo dia. Mas ressalve-se que houve somente 1 evento de troca de $C E O$ fundamentado na "Reestruturação do Board", conforme mostra a Tabela1.

Em função da dinâmica do mundo corporativo, as notícias sobre negócios tendem a ter vida curta. Quando a mesma notícia estava repetida em mais de um dia na base Bloomberg® denotou uma importância maior do que quando divulgada somente em um dia. Mas somente as justificativas "Desempenho" e "Provocado por Mudanças Políticas de Governo" tiveram a mesma notícia divulgada em mais de um dia nesta mídia, denotando a importância destas justificativas.

Quando a notícia sobre o turnover foi divulgada na plataforma do Bloomberg® e simultaneamente em outras mídias especializadas, em mais de um dia, significou que foi considerada mais importante do que outras. Nesta pesquisa, somente a justificativa "Deixar o cargo para permanecer apenas no Conselho de Administração" teve divulgação simultânea em mais de um dia na Bloomberg® e em outras mídias especializadas.

As notícias sobre o turnover do CEO podem ser exclusivas, ou seja, tratarem somente deste fato, ou serem divulgadas em meio a outras. A segunda forma demonstra uma menor importância atribuída para o evento. As justificativas da Dimensão Forçada mostraram que a maioria das notícias foram exclusivas e excepcionalmente o assunto foi divulgado em meio a outras notícias, demonstrando então a sua importância.

Quando a notícia tem uma manchete sobre o turnover é porque a mídia pretendeu atrair a atenção do leitor em maior proporção do que se a manchete fosse evasiva ou não existisse. Com exceção das justificativas da Dimensão Voluntária, todas as demais justificativas apresentaram alto índice de intensidade de notícias com manchete específica. Este achado é coerente com a exclusividade das notícias sobre o evento. A divulgação da mesma notícia em mais de um meio no mesmo dia demonstra uma repercussão maior sobre o evento. Mas foram poucas as notícias com esta característica. Os achados mostram que aproximadamente $91 \%$ das notícias foram divulgadas em mídias exclusivas da área econômica, que são as mais acessadas pelos investidores.

\section{CONCLUSÕES}

A classificação proposta por Parrino (1997) demonstrou que predomina no cenário brasileiro o turnover forçado (97\%) em detrimento do turnover voluntário. Esses dados confirmam os achados de Lausten (2002) e Jenter e Lewellen (2014) sobre as dimensões forçada e voluntária. O estudo também revelou uma tendência de aumento na troca de comando das empresas, em especial quando o desempenho é insatisfatório, inobstante o mercado de capitais do país seja pequeno e a propriedade seja concentrada. Os resultados apontam que as trocas de CEOs no período passaram de 2 em 2010 para 9 em 2014, confirmando os estudos de Kaplan e Minton (2012) de tendência de aumento no turnover. A regulação exige que seja divulgada a troca do $C E O$, mas não obriga a companhia a divulgar a justificativa desta troca, o que pode explicar a falta de divulgação das justificativas de 32 eventos de troca de $C E O$.

A maior parte dos eventos veiculados na mídia referem-se a troca de $C E O$ s de companhias com participação de fundos de pensão fechados estatais em decorrência da relevante participação destes no mercado de capitais.

Foi observado que todas as notícias divulgadas ocorreram em dias diferentes da data de reunião do conselho de administração e houve maior interesse de divulgação pelos veículos específicos da área do mercado financeiro. A veiculação das notícias se dispersaram ao longo da janela de eventos, mesmo aquelas replicadas em outros meios, além da base Bloomberg ${ }^{\circledR}$. No entanto, a base de dados Bloomberg ${ }^{\circledR}$ foi a que mais divulgou as notícias que poderiam impactar rapidamente nas decisões dos investidores institucionais. Outras mídias não atribuíram a mesma importância às notícias de turnover, ficando clara a efemeridade das notícias sobre a troca de CEOs em companhias que possuem Fundos de Pensão em seu quadro de investidores institucionais.

Ressalta-se que as notícias divulgadas na plataforma do Bloomberg® atingem um público específico, que é o grande investidor, que pode reagir às notícias divulgadas, dependendo do julgamento que faz. Em função disto, foi observado se a notícia do turnover estava divulgada na plataforma do Bloomberg ${ }^{\circledR}$. O resultado mostrou que o turnover do $C E O$ "Provocado por Mudanças Políticas de Governo" foi a que teve maior divulgação na plataforma, o que denota a importância do $C E O$ na gestão das companhias controladas pela Administração Pública, a exemplo do caso icônico da Petrobras. 
Observou-se grande interesse dos players do mercado de capitais sobre o "Desempenho" porque as mídias tendem a intensificar a divulgação de notícias em que percebem potencial para maior repercussão. A justificativa "Permanecer apenas no Conselho" é de natureza transitória porque ocorreu para determinada situação e que tende a não se repetir nos períodos futuros. Em razão disto, a justificativa "Desempenho" foi aquela que predominou no período pesquisado, confirmando os estudos de Jenter e Kanaan (2015). Esta pesquisa não teve como objetivo identificar o cumprimento das exigências legais, mas a extensão atribuída pelas mídias especializadas às dimensões forçadas e voluntárias da troca de CEOs em companhias com participações societárias de fundos de pensão fechado.

Em razão de que a pesquisa contemplou dados anuais, admite-se o risco da existência de mais de uma troca no decorrer do ano sem que esta mudança tenha sido identificada. Este risco é mitigado na medida em que o turnover de $C E O$ não é um evento frequente em face das eventuais consequências advindas. Os resultados sobre as justificativas voluntárias devem ser avaliados com cautela em razão da ocorrência de apenas um evento, o que caracteriza uma limitação do estudo. Inobstante alguns pesquisadores tenham direcionado seus esforços para classificar as justificativas entre forçada e voluntária, esta divisão ainda é permeada por alguma subjetividade inerente a esta tipologia de pesquisa, o que constitui uma limitação do estudo. Ainda, as justificativas encontradas nas publicações que compõem a pesquisa podem ser diferentes das verdadeiras causas das trocas dos CEOs em função dos riscos das mídias divulgarem matérias preparadas pelas próprias companhias.

Outro aspecto importante de mencionar foi a constatação de que dos 65 eventos sobre turnover de CEOs no período em análise, as mídias divulgaram apenas sobre 33, demonstrando baixo nível de veiculação dessas informações aos stakeholders. No entanto, ressalta-se que a obrigação das companhias de comunicar a troca de $C E O s$ à $\mathrm{CVM}$ e à $\mathrm{BMF} \& B$ Bvespa ocorreu de acordo com as determinações regulatórias. Embora as companhias tenham o dever legal de comunicar a troca do $C E O$, este dever não se estende para as justificativas da troca. Em razão disto, observou-se na pesquisa que 32 eventos de trocas de CEOs (49\%) não tiveram as suas justificativas divulgadas. Desta forma, sugere-se que esta perspectiva seja incluída em pesquisas futuras.

A maior divulgação do turnover, poderia, supostamente, impactar na precificação dos ativos, positiva ou negativamente. As pesquisas encontradas demonstram os efeitos da divulgação do turnover de CEO no mercado de capitais. No entanto, não foram encontrados estudos que avaliem os efeitos da possível relação entre a intensidade da divulgação das justificativas da troca com a precificação dos ativos da companhia, mostrando uma lacuna a ser explorada.

\section{REFERÊNCIAS}

ABRAPP. Associação Brasileira das Entidades Fechadas de Previdência Complementar. Consolidado estatístico. Recuperado em 18 de agosto de 2017 em: http://www.abrapp.org.br/Consolidados/Consolidado \%20 Estat\%C3\%ADstico_04_2017.pdf.

Agrawal, A., Jaffe, J. F., \& Karpoff, J. M. (1999). Management turnover and governance changes following the revelation of fraud. Journal of Law and Economics, 42, p. 309- 342.

Bardin, L. (2010). Análise de conteúdo. $5^{\mathrm{a}}$ ed. Lisboa: Edições 70.

Boehmer, E., \& Kelley, K. E. (2009). Institutional investors and the informational efficiency of prices. Review of Financial Studies, 22, 3563-3594.

Brunello, G., Graziano, C., \& Parigi, B. M. (2003). CEO turnover in insider-dominated boards: The Italian case. Journal of Banking \& Finance, v. 27, n. 6, p. 1027-1051.

Bushman, R., Dai, Z., \& Wang, X. (2010). Risk and CEO turnover. Journal of Financial Economics, v. 96, n. 3, p. 381-398.

Campbell, T. C., Gallmeyer, M., Johnson, S. A., Rutherford, J., \& Stanley, B. W. (2011). CEO optimism and forced turnover. Journal of Financial Economics, 101(3), 695-712.

Cheung, W. J., \& Jackson, A. B. (2012). Chief Executive Officer departures and market uncertainty. Australian Journal of Management, p. 0312896212450040.

De Dreu, J., \& Bikker, J. A. (2012). Investor sophistication and risk taking. Journal of Banking \& Finance, v. 36, n. 7, p. 2145-2156.

Del Guercio, D., \& Tkac, P. A. (2002). The Determinants of the Flow of Managed Portfolios: Mutual Funds vs. Pension Funds. The Journal of Financial and Quantitative Analysis, Vol. 37, n. 4, pp. 523-557. 
Defond, M., \& Park, C. W. (1999). The effect of competition on CEO turnover. Journal of Accounting and Economics, v. 27, n. 1, p. 35-56.

Denis, D. J., Denis, D. K., \& Sarin, A. (1997). Ownership structure and top executive turnover. Journal of financial economics, v. 45, n. 2, p. 193-221.

Dissanaike, G., \& Papazian, A. (2004). Management turnover in stock market winners and losers: a clinical investigation. ECGI-Finance Working Paper, n. 61.

Engel, E., Hayes, R. M., \& Wang, X. (2003). CEO turnover and properties of accounting information. Journal of Accounting and Economics, v. 36, n. 1, p. 197-226.

Faccio, M., \& Lang, L. HP. (2002). The ultimate ownership of Western European corporations. Journal of financial economics, v. 65, n. 3, p. 365-395.

Fletcher, C. E. (1988). Sophisticated Investors Under the Federal Securities Laws. Duke Law Journal, p. 10811154.

Gomes, M. G. (2014). Relação entre captação e desempenho: uma investigação do comportamento de investidores pessoas físicas e institucionais. 75 f. Dissertação (Mestrado) - Escola de Economia de São Paulo. São Paulo.

Hand, J. R. M. (1990). A test of the extended functional fixation hypothesis, The Accounting Review, 740-763.

Huson, M. R., Malatesta, P. H., \& Parrino, R. (2004). Managerial succession and firm performance. Journal of Financial Economics, v. 74, n. 2, p. 237-275.

James, C., \& Karceski, J. (2002). Captured money? Differences in the performance characteristics of retail and institutional mutual funds. Unpublished working paper. University of Florida.

Jenter, D., \& Kanaan, F. (2015). CEO turnover and relative performance evaluation. The Journal of Finance.

Jenter, D., \& Lewellen, K. (2014). Performance-induced CEO turnovers. Working Paper. Stanford University.

Johnson, W. B., Magee, R. P., Nagarajan, N. J., \& Newman, H. A. (1985). An analysis of the stock price reaction to sudden executive deaths. Journal of Accounting and Economics. North-Holland, v. 7, p. 151-174.

Kang, J., \& Shivdasani, A. (1995). Firm performance, corporate governance, and top executive turnover in Japan. Journal of financial economics, v. 38, n. 1, p. 29-58.

Kaplan, S. N., \& Minton, B. A. (2012). How has CEO turnover changed?. International Review of Finance, v. 12 , n. 1, p. $57-87$

Lausten, M. (2002). CEO turnover, firm performance and corporate governance: empirical evidence on Danish firms. International Journal of Industrial Organization, v. 20, n. 3, p. 391-414.

Maroco, J., \& Garcia-Marques, T. (2006). Qual a fiabilidade do alfa de Cronbach? Questões antigas e soluções modernas? Laboratório de Psicologia, v. 4, n. 1, p. 65-90.

Murphy, K. J., \& Zabojnik, J. (2007). Managerial capital and the market for CEOs. Available at SSRN 984376.

Murphy, K. J., \& Zimmerman, J. L. (1993). Financial performance surrounding CEO turnover. Journal of Accounting and Economics, v. 16, n. 1, p. 273-315.

Parrino, R. (1997). CEO turnover and outside succession a cross-sectional analysis. Journal of financial Economics, v. 46, n. 2 , p. $165-197$.

Rachpradit, P., Tang, J. Cs., \& Ba Khang, D. (2012). CEO turnover and firm performance, evidence from Thailand. Corporate Governance: The international journal of business in society, v. 12, n. 2, p. 164-178.

Riberi Punsuno, F., Kazuo Kayo, E., \& Ayres Barreira de Campos Barros, L. (2007). O ativismo dos fundos de pensão e a qualidade da governança corporativa. Revista Contabilidade \& Finanças - USP, 18 (45).

Worrell, D. L., Davidson, W. N., \& Glascock, J. L. (1993). Stockholder reactions to departures and appointments of key executives attributable to firings. Academy of Management Journal, v. 36, n. 2, p. 387-401. 